ination. On leaving Cambridge he worked for a time with Messrs. Kelvin and James White, of Glasgow, on researches relating to electrical and magnetic problems. Later he held, in turn, lectureships in electrical engineering at the Rutherford Technical College, Newcastle-on-Tyne, and at the Borough Polytechnic, London.

In 1915 Tomlinson was appointed to a post at the National Physical Laboratory, where he was first engaged, during the War of 1914-18, on the verification of gauges. From this he turned his attention to devising apparatus for the measurement of gears and gear-cutting hobs, then almost a new field, with which he continued to be closely associated for the rest of his life, developing further methods and instruments for checking the accuracy of gears of all sizes, and of the hobbing machines used in their production. In this subject he became a recognized expert whose advice was sought both by government departments and by private firms.

Among other matters Tomlinson also devoted himself successfully to the study of molecular cohesion in relation to surface phenomena such as pressure corrosion and friction. Following this, he became interested in the geometrical properties of surfaces, and devised the now well-known surface-finish recorder which bears his name, and which is an ex. cellent example of his direct attack on a problem, and his faculty for attaining results by the simplest means.

An altogether different line of work was in connexion with the improvement of time-keepers. $\mathrm{He}_{\boldsymbol{\theta}}$ spent much time on the development of a new type of vibration clock, and in experiments on new methods for driving free pendulum clocks. Incidentally to this work, he designed a new type of chronograph for the comparison of time-signals to an accuracy of $0 \cdot 1$ millisecond.

Tomlinson had a flair for instrument design which amounted to genius. More often than not he would make the first model of a new instrument with his own hands, using the material nearest to hand. But though these first models might have a somewhat gimerack appearance they were always usable tools and, being usually designed to meet some immediate need, were often put into practical service for considerable periods before, as happened in many cases, their proved utility made it desirable to re-design them in a form suitable for commercial production.

Tomlinson-"Tommy" to his friends-had a charming and lovable personality. Modest and unassuming, he was always ready with advice and help for others, and a source of inspiration to those who worked with him. He was a rare combination of man of science and practical engineer, and his death is a national loss. He leaves a widow and two sons.

J. E. SEars.

\section{Dr. J. N. Sugden}

DR. JAMES N. SUGDEN, senior lecturer in inorganic chemistry in the Imperial College of Science and Technology, who was killed by a flying bomb on July 11, 1944, was born at Silsden, near Keighley, on March 27, 1894. As a pupil of the Trade and Grammar School, Keighley, he came under the influence of a former student of chemistry in the Royal College of Science, Mr. Harry Harper, and after a period of study at the Technical College, Huddersfield, he proceeded to South Kensington in 1913.
Having graduated as an associate with first-class honours, and having been awarded the Neil Arnott Studentship and a Royal Scholarship, Sugden devoted himself to investigations which naturally soon became closely related to war problems. He received a commission in the Army, and under the direction of the late Prof. H. Brereton Baker he took part in some of the early scientific work which arose out of the enemy's use of poison gas. Later he was much concerned with the technical development of methods and equipment for ensuring an adequate supply of safe drinking water for troops dependent on contaminated supplies, particularly in France and in Mesopotamia. Under his immediate supervision, large mobile and static chlorination plants with their control laboratories were designed, tested, dispatched, and operated. Returning in 1919 from a prolonged visit to Iraq, he was appointed a demonstrator in chemistry at the Royal College of Science (Imperial College of Science and Technology); he was promoted to be a lecturer in 1922, and senior lecturer in 1943. There he quickly established a reputation as a most conscientious and efficient teacher.

Sugden's methods were often ingenious, and sometimes unorthodox; for he was an individualist whose acidulated epigrams were a tonic to the laggard, but whose meticulous care and patient instruction were an inspiration to every diligent student. Prolonged ill-health restricted the scope of his physical activity, but his mind seemed the more acute. His principal contribution to chemical knowledge concerned the hydration of salts in aqueous solution. This study yielded most interesting results; but he placed his teaching duties before all other attractions, and never regained the physical strength to pursue the inquiry.

Sugden was not an easy man to know. His bachelor life was lonely, and his friends, deliberately few, scattered by the march of time. He was interested in British silver coins, and liked to try his hand at the more erudite literary competitions in periodicals, especially those involving a foreign language. He was a judge of burgundy, and his efforts as an amateur photographer disclosed an artistic perception. While few could phrase a rebuke more mordantly, few enjoyed more gloomily the humour of life or more often delighted their acquaintances with gleanings among the unusual, the comic, or the profound. By his colleagues, as well as by many of the students to whom he ministered for twenty-five years, he will be remembered with affection and with the respect due to one who, having well considered, possessed the courage of his convictions. A. A. ELDRIDGE.

\section{Prof. B. B. Ray}

Prof. B. B. RAY, Khaira professor of physics in the University of Calcutta, died on July 29, 1944. He was a fellow of the National Institute of Sciences of India; and presided over the Physics Section of the twenty-ninth session of the Indian Science Congress, held at Baroda in 1942. Prof. Ray joined the University of Calcutta in 1921 as a lecturer in physies and was one of the early batch of students who carried out research work in physics under Sir C. V. Raman.

Prof. Ray visited Europe twice, once in 1923 and again in 1935. During his first visit he worked at Uppsala in the laboratory of Prof. M. Siegbahn and at Copenhagen under Prof. Niels Bohr. It was in Prof. Siegbahn's laboratory that Prof. Ray learned 